\title{
Espacialidades Sonoras na Arte Contemporânea
}

\author{
Sound Spatialities in Contemporary Art
}

\section{Espacialidades Sonoras en el Arte Contemporáneo}

NUNES, Cristiane dos Guimarães Alvim ${ }^{1}$ BORDA, Luis Eduardo dos Santos²

${ }^{1}$ Faculdade de Arquitetura e Urbanismo e Design, Programa de Pós-graduação em Arquitetura e Urbanismo, Universidade Federal de Uberlândia, Uberlândia - MG, Brasil. dosguimaraes@hotmail.com ORCID: 0000-0002-3887-6660 2 Faculdade de Arquitetura e Urbanismo e Design, Programa de Pós-graduação em Arquitetura e Urbanismo, Universidade Federal de Uberlândia, Uberlândia- MG, Brasil. luiseduardoborda@yahoo.com.br ORCID: 0000-0001-7831-8164 


\title{
Resumo
}

Este artigo apresenta um estudo sobre determinadas especificidades da Arte Sonora, produção artística contemporânea que utiliza o som como elemento fundamental da obra. Contextualiza a Arte Sonora no ambiente da Arte Contemporânea e aprofunda alguns aspectos deste tipo de arte, a saber: espacialidade, sensorialidade, interatividade, sonoridade e visualidade. Com base nestes aspectos, o texto analisa três obras sonoras. Constata que o caráter ambiental (ou a espacialidade) de tais trabalhos é um aspecto que os vincula à Arte Contemporânea e também os aproxima do campo da Arquitetura. A análise aponta a forte presença dos aspectos sensoriais dos trabalhos, seu caráter interativo, o investimento nos aspectos visuais e também os diferentes e instigantes resultados sonoros de tais produções.

Palavras-Chave: Arte Sonora; Instalação Sonora; Sensorialidade na Arte; Espacialidade na Arte; Arte e Interatividade

\begin{abstract}
This article presents a study on certain specificities of Sound Art, a contemporary artistic production that uses sound as a fundamental element of the work. Contextualizes Sound Art in the Contemporary Art environment and deepens some aspects of this type of art, namely: spatiality, sensoriality, interactivity, sonority and visuality. Based on these aspects, the text analyzes three sound works. It finds that the environmental character (or the spatiality) of such works is an aspect that links them to Contemporary Art and also brings them closer to the field of Architecture. The analysis points to the strong presence of the sensory aspects of the works, their interactive character, the investment in visual aspects and also the different and exciting sound results of such productions.
\end{abstract}

Key-Words: Sound Art; Sound Installation; Sensoriality in Art; Spatiality in Art; Art and Interactivity

\section{Resumen}

Este artículo presenta un estudio sobre ciertas especificidades de Arte Sonoro, producción artística contemporánea que utiliza el sonido como elemento fundamental de la obra. Contextualiza el Arte Sonoro en el entorno del Arte Contemporáneo y profundiza algunos aspectos de este tipo de arte, a saber: espacialidad, sensorialidad, interactividad, sonoridad y visualidad. Basándose en estos aspectos, el texto analiza tres obras sonoras. Constata que el carácter ambiental (o la espacialidad) de tales trabajos es un aspecto que los vincula con el Arte Contemporáneo y también los acerca al campo de la Arquitectura. El análisis apunta a la fuerte presencia de los aspectos sensoriales de los trabajos, su carácter interactivo, la inversión en los aspectos visuales y también los diferentes e instigadores resultados sonoros de tales producciones.

Palabras clave: Arte Sonoro; Instalación Sonora; Sensorialidad en el Arte; Espacialidad en el Arte; Arte e Interactividad 


\section{Introdução}

O presente estudo investiga a Arte Sonora e analisa alguns de seus aspectos. ${ }^{1}$ Produção artística contemporânea, este tipo de arte utiliza o som como elemento fundamental e apresenta um repertório rico e diversificado. As obras de Arte Sonora costumam ser fortemente sensoriais, além de se completarem a partir da interação com o público, muitas vezes. Frequentemente, também revelam um caráter ambiental, o que as aproxima do campo da arquitetura. Além de proporcionarem sonoridades instigantes e possuírem caráter marcante, também revelam preocupação com os aspectos visuais. $O$ estudo considera, ainda, a tecnologia utilizada, o tempo que demandam e, por fim, determinados significados que deixam em aberto.

Tendo por objetivo a contextualização deste tipo de arte no âmbito da Arte Contemporânea, o texto traz uma abordagem sobre as mudanças ocorridas nas concepções espaciais vinculadas à Arte Moderna e à produção Contemporânea. Para isso, recorre às abordagens de Alberto Tassinari (2001), Miwon Kwon (2002) e Rosalind Krauss (2008), entre outros autores. Este entendimento contribui para a compreensão da espacialidade das obras contemporâneas e, dentro disso, para o entendimento de sua interface com a arquitetura. Em face desta aproximação com a arquitetura, a propósito, o texto recupera também determinadas discussões acerca de aspectos arquitetônicos (PALLASMAA, 2011; ZEVI, 2009; TUAN, 1983) e que passam a comparecer, deste modo, em tais produções. Aborda, ademais, a questão do "campo ampliado" da escultura e também da Arquitetura, questões teóricas que se vinculam aos trabalhos em pauta. (KRAUSS, 2002; VIDLER, 2013; FOSTER, 2017).

O texto começa discutindo a especificidade da Arte Sonora e seu surgimento. Para isso, utiliza as abordagens de Lilian Campesato (2007), de Mikel Arce Sagarduy (2014) e de Manuel Rocha Iturbide (2017). Tais abordagens também contribuem para o entendimento sobre a dimensão do repertório da Arte Sonora e chamam a atenção, ainda, para seu caráter híbrido, ou seja, para a sua imbricação com outras linguagens (Arquitetura, Música e algumas linguagens visuais). Por fim, o estudo aborda três instalações sonoras e as analisa a partir de aspectos como espacialidade, visualidade, sonoridade, tempo, tecnologia, interatividade, etc. As obras são Lines (2016), do compositor sueco Anders Lind; Oasi (2014), da escultora italiana Licia Galizia e do compositor italiano Michelangelo Lupone e, finalmente, 329 Prepared Dc-Motors, Cotton Balls, Toluene Tank (2013), do artista suíço Zimoun. Além destas obras, o estudo faz menção a outros trabalhos sonoros, algo que as contextualiza e amplia a abordagem dos aspectos investigados.

\section{Especificidades da Arte Sonora}

As primeiras manifestações artísticas sonoras começaram em meados da década de 1970 e, a partir daí, motivaram uma produção com caráter diversificado e que englobou várias outras linguagens, como a Música e a Arquitetura. (CAMPESATO, 2007). Assim, observamos que a Arte Sonora se apresenta como uma arte intermedia, uma vez que mantém interfaces com outras linguagens. Adota práticas híbridas entre diferentes campos da arte. Além disso, quase sempre, proporciona uma experiência imersiva e sensorial. A percepção do público acontece não exclusivamente através da audição, mas também da visão. (SAGARDUY, 2014).

A Instalação, o Happening e a Música Eletroacústica, novidades introduzidas na arte entre as décadas de 1950 e 1970, foram a base deste novo tipo de experiência artística. A Instalação², por exemplo, desencadeou um processo de extrapolação dos conceitos artísticos usuais e integrou o espaço

\footnotetext{
${ }^{1}$ Este trabalho é parte das reflexões e resultados apresentados na dissertação de mestrado intitulada Instalações Sonoras Contemporâneas: Espaço e Sensorialidade. A dissertação, de autoria de Cristiane dos G. A. Nunes e tendo orientação do prof. Dr. Luis E. S. Borda, foi desenvolvida junto ao Programa de Pós-Graduação em Arquitetura e Urbanismo (PPGAU) da Faculdade de Arquitetura e Urbanismo e Design, da Universidade Federal de Uberlândia, no período entre 2017 e 2019.

2 Trabalho artístico com caráter ambiental.
} 
(ambiente) à obra de arte. Além disso, possibilitou que o público imergisse na obra e interagisse com ela, deixando de ser apenas um espectador. A participação do público foi importante no sentido de completar a obra, inclusive. ${ }^{3}$ (CAMPESATO, 2007). No que concerne à Música Eletroacústica, sua contribuição à Arte Sonora foi a incorporação de novas tecnologias, a manipulação e a montagem de sons gravados, a utilização de instrumentos não convencionais e a exploração de novas sonoridades. Isso contribuiu para a transformação das produções musicais, gerou a Música Concreta e novas formas de escuta. ${ }^{4}$ (CAMPESATO, 2007; SAGARDUY, 2014). Por fim, a incorporação do som às produções artísticas aconteceu, também, através do Happening. Manifestação artística que se desenvolveu a partir da ação de um ou mais artistas, o Happening tem caráter efêmero e implica variações no que concerne ao tempo (duração) e à utilização do espaço (o ambiente da ação). 0 Grupo Fluxus foi um dos pioneiros deste tipo de expressão artística e produziu performances que envolveram Música, Dança, Teatro e Artes Visuais. (CAMPESATO, 2007; SAGARDUY, 2014). As apresentações experimentais do Fluxus requisitavam a participação do espectador e estimulavam diferentes sentidos, pois envolviam uma combinação de objetos, sons, luzes e movimento. ${ }^{5}$

Tendo por base esses antecedentes, a Arte Sonora se instituiu como gênero artístico por volta da década de 1980. (CAMPESATO, 2007; SAGARDUY, 2014). A partir daí, as produções conquistaram cada vez mais visibilidade. As primeiras exposições e festivais desse novo gênero começaram a ser realizados na passagem do século XX para o século XXI. Através do Festival Sonambiente (realizado em duas edições: 1996-2006), por exemplo, a Alemanha se firmou como um dos principais polos de promoção e divulgação deste novo tipo de arte. (CAMPESATO, 2007). ${ }^{6}$

Dentre as produções de Arte Sonora, destacam-se dois tipos que se baseiam na linguagem das artes visuais: a instalação sonora e a escultura sonora. A instalação sonora apresenta um caráter ambiental e se concentra, muitas vezes, na tecnologia eletroacústica. Já a escultura sonora está mais voltada para o objeto e se utiliza principalmente de recursos mecânicos. Comenta Campesato (2007), aliás, que "o termo escultura sonora se relaciona com objetos que produzem ou que provocam a produção de sons, enquanto [...] na instalação, os sons tendem a ser utilizados para criar o contexto e o espaço da obra". (CAMPESATO, 2007, p. 74).

Considera o artista Manuel Rocha Iturbide que a escultura sonora e a instalação sonora se enquadram no conceito de campo expandido, adotado pela historiadora Rosalind Krauss. Segundo o artista, a escultura e a instalação se tornam "obras expandidas" no momento em que incorporam o som. (ITURBIDE, 2017).

Já Campesato (2007) analisa a Arte Sonora a partir de cinco aspectos: sonoridade, tecnologia, interação, espaço e tempo. Segundo a autora, tais aspectos são elementos fundamentais desse tipo de arte. Além desses cinco aspectos, incluímos no presente estudo a abordagem de aspectos visuais,

\footnotetext{
${ }^{3}$ A instalação Tropicália (1967) do artista plástico brasileiro Hélio Oiticica (1937-1980) é um exemplo do público como parte integrante da obra. Oiticica foi um artista original e inovador; através de suas proposições e conceitos, destacou-se no cenário da Arte Contemporânea no Brasil.

${ }^{4}$ A música concreta teve o compositor e teórico francês Pierre Schaeffer (1910-1995) como um de seus maiores expoentes. Duas ideias centrais se destacam no pensamento de Schaeffer: os conceitos de objeto sonoro e de escuta reduzida. (CAMPESATO, 2007; SAGARDUY, 2014). Para conhecer os conceitos de Schaeffer para objeto sonoro e escuta reduzida, consultar CHION (2009, p. 30-33).

${ }^{5}$ O Grupo Fluxus teve grande influência da música experimental do compositor estadunidense John Cage (19121992), nome que também contribuiu para a produção de Arte Sonora. Suas concepções sobre som e silêncio, tempo e espaço, contribuíram para uma redefinição das regras e funções tanto do artista e sua obra como do público. Cage procurou valorizar mais o processo de criação que a obra finalizada. (CAMPESATO, 2007, p. 50).

${ }_{6}^{6}$ Outros festivais têm surgido. Na Espanha, por exemplo, acontece desde 2005 o In-Sonora, Festival de Arte Sonora e Interativa (https://in-sonora.org/). Em Portugal, aconteceu em setembro de 2019 a quarta edição do festival Lisboa Soa (https://www.lisboasoa.com/). Além dos festivais, existem atualmente sites dedicados à divulgação de trabalhos de artistas sonoros, como o Those Who Make Waves - TWMW (https://thosewhomakewaves.wordpress.com/) e o Leerraum [ ] (http://www.leerraum.ch/), entre outros.
} 
sensoriais e de alguns significados deixados em aberto pelas obras. Tais aspectos, apresentados a seguir, subsidiarão a análise das obras discutidas na segunda parte deste trabalho.

\subsection{Espacialidade}

Observa o crítico de arte Alberto Tassinari (2001) que a nova concepção cubista acerca do espaço foi muito importante para a Arte Moderna. No que se refere ao espaço da pintura (a tela), levou à ruptura entre fundo e figura. Na escultura, levou a esse mesmo resultado: o objeto escultórico abandonou o pedestal (o equivalente ao contorno, na pintura) e passou a ser, até certo ponto, um objeto como outro qualquer no mundo. Por fim, as construções artísticas tridimensionais passaram a configurar ambientes que o espectador-visitante pode experienciar. "A eliminação radical do contorno de uma escultura a deixará sem um espaço próprio, unificador, e [...] o espaço do mundo em comum é que será seu complemento", comenta a esse respeito Alberto Tassinari. (TASSINARI, 2001, p. 44). É o que acontece em muitos trabalhos contemporâneos, inclusive na Arte Sonora: adquirem um caráter quase arquitetônico; são um ambiente no qual o espectador entra.

A historiadora de arte Rosalind Krauss (2008) também discute as transformações pelas quais passou a escultura tanto na Arte Moderna quanto na Contemporânea. Krauss (2008) observa que a escultura incorporou outras linguagens (pintura, fotografia, música, performance, arquitetura, etc.), o que provocou um alargamento de seu campo de ação. Tornou-se intermedia, isto é, passou a misturar categorias que antes funcionavam de modo separado. É isso o que Krauss (2008) quer dizer quando fala em "campo ampliado da escultura". No que se refere à questão do espaço, observa que muitas obras contemporâneas são trabalhos ambientais, o que as aproximou da arquitetura. ${ }^{7}$

A Land Art e o Site-Specific, movimentos dos anos 1960 e 1970, são exemplo desses trabalhos ambientais, estabelecidos no meio urbano ou na natureza e que subverteram a tradição da escultura. É o caso de Titled Arc (Federal Plaza, New York, 1981), do artista americano Richard Serra. Tendo caráter ambiental, já que articulado à praça onde se estabelecia, este trabalho também inaugurou o conceito de Site-Specific, aliás: fora concebido para as condições particulares daquele lugar, condições não somente físicas, mas culturais e políticas. Fora daquele espaço, perdia seu sentido. ${ }^{8}$

Prosseguindo a discussão de Krauss (2008), o teórico Anthony Vidler observa que a arquitetura contemporânea também passou a ampliar seu campo. Para Vidler (2013), isso aconteceu a partir dos anos 1960, quando a arquitetura começou a se utilizar da "abstração como linguagem formal" (VIDLER, 2013, p. 245). Vidler (2013) destaca que a ampliação do campo da arquitetura passou a acontecer, ainda, a partir das diferentes combinações entre "arquitetura e paisagem", "arquitetura e biologia", "arquitetura e programa", "arquitetura e arquitetura". Próximo do pensamento de Krauss, portanto, Vidler (2013) ressalta a produção de "novas visões de 'não paisagem' e 'não escultura' que são, contudo, não exatamente arquitetura. Ou, pelo menos, 'não exatamente arquitetura' tal como temos experimentado a arquitetura até hoje." (VIDLER, 2013, p. 250). ${ }^{9}$

\footnotetext{
7 Um exemplo disso é a instalação Riverbed (2014), do artista dinamarquês Olafur Eliasson. Realizada no Louisiana Museum of Modern Art (Dinamarca), consiste na passagem de uma calha de água por dentro do museu. A água vem de um rio próximo. É como se o artista criasse um braço do rio e o fizesse passar por dentro do espaço museológico. Com isso, proporciona uma experiência imersiva e sensorial ao visitante. Riverbed adquire uma dimensão espacial própria da Arte Contemporânea; ali, arte, natureza e arquitetura se misturam e se completam.

${ }^{8}$ Dando prosseguimento a essas discussões, aliás, a crítica e historiadora da arte Miwon Kwon (2002) acompanha os novos desdobramentos da questão espacial na Arte Contemporânea. Observa que, diferente do site-specific (instalação criada para um espaço determinado), a Arte Contemporânea passou a lidar com um novo tipo de lugar. Em muitas obras, lugar passou a ser uma questão (a mulher, o índio, o negro, etc.), uma página de jornal, a própria instituição museológica ou o mercado de arte, etc. A isto denominou site-oriented art. (KWON, 2002).

${ }^{9}$ Segundo o teórico, no início do século XXI, quatro princípios contribuíram para a ampliação do campo da arquitetura: as "ideias de paisagem" nas construções de modelos digitais, as "analogias biológicas" ("bioformas"),
} 
As reflexões do crítico e historiador de arte Hal Foster sobre a relação (ora colaborativa, ora competitiva) entre as práticas contemporâneas, no campo da arte e da arquitetura, também contribuem para as discussões sobre esse mesmo campo ampliado. Do mesmo modo que Rosalind Krauss, Foster (2017) comenta o Tilted Arc (New York, 1981), de Richard Serra, obra que se tornou uma referência para o entendimento das novas questões colocadas pela Arte Contemporânea. Segundo Foster (2017), Serra trabalhou a relação desta obra tanto com o lugar quanto com o espectador. Neste trabalho, redefiniu a estrutura do lugar e envolveu o movimento do corpo do espectador. Foster (2017) destaca três princípios que direcionaram Serra para uma "compreensão da escultura como estruturação de materiais com o fim de motivar um corpo e demarcar um lugar" (FOSTER, 2017, p. 167). São eles: o princípio "construtivista" (relacionado ao material), o princípio "fenomenológico" (relacionado à ativação do corpo do espectador) e o princípio "situacional" (relacionado à especificidade do lugar). (FOSTER, 2017, p. 167).

No caso específico da Arte Sonora, há a incorporação destas mesmas questões (princípio construtivista, fenomenológico e situacional). Isso porque muitas das obras sonoras se configuram como ambientes; são espaços que o espectador-visitante percorre e que ativam seus sentidos. Muitas delas implicam, até mesmo, a manipulação de elementos da obra pelo próprio espectador. Focalizemos, então, algumas considerações arquitetônicas que se tornam aplicáveis à Arte Sonora, desde que tem funcionado, muitas vezes, enquanto um ambiente.

O teórico italiano Bruno Zevi (1918-2000), por exemplo, destaca a importância de se compreender a essência do edifício, ou seja, sua espacialidade. Zevi (2009) observa que essa essência só é percebida através da experiência direta com o próprio espaço. Isso implica a questão do tempo, ou seja, o período que se leva para percorrer o espaço e capturar as diferentes imagens (do objeto e/ou do espaço) que se modificam ao longo do percurso. Para o autor, "todas as obras de arquitetura, para serem compreendidas e vividas, requerem o tempo da nossa caminhada". (ZEVI, 2009, p. 23). Esta mesma discussão passou a comparecer nos ambientes da Arte Contemporânea, incluindo aí os da Arte Sonora.

Outra discussão arquitetônica, e que passou a ser também tratada nos espaços ambientais da Arte Contemporânea, é o que diz respeito à experiência sensorial que o espaço proporciona. Essa é uma reflexão do geógrafo sino-americano Yi-Fu Tuan, por exemplo, para quem a experiência é uma forma de conhecimento. Tuan chama a atenção para as ricas e sutis experiências sensoriais que os espaços proporcionam. (TUAN, 1983). Do mesmo modo, os ambientes artísticos contemporâneos (inclusive aqueles propostos pela Arte Sonora) vêm proporcionando ao público experiências sensoriais enriquecedoras.

O arquiteto e teórico finlandês Juhani Pallasmaa também aborda a importância das experiências sensoriais proporcionadas pelo espaço arquitetônico. Para Pallasmaa (2011), os aspectos sensoriais reforçam nossa relação com o espaço. Observa que a "grande missão de qualquer arte significativa" é despertar nossa sensação de realidade e possibilitar que criemos uma identidade com determinado lugar. (PALLASMAA, 2011, p. 11). O autor também chama a atenção para o fato de que, quando pensamos os ambientes arquitetônicos, também consideramos a "projeção do corpo humano e de seu movimento no espaço". (PALLASMAA, 2011, p. 43).

Algumas questões tratadas pela arquitetura passaram a ser objeto, portanto, dos ambientes artísticos contemporâneos. Passaram a também estar implicadas na Arte Sonora, desde que muitas das propostas sonoras têm se configurado como espacialidades e têm trazido consigo questões arquitetônicas (espaço, tempo, estrutura visual, sensorialidade, etc.).

os "novos conceitos" de programa (realidade global, política, social e econômica) e a busca por uma linguagem arquitetônica a partir de suas próprias práticas. (VIDLER, 2013, p. 248). 


\subsection{Interatividade}

A interatividade é um aspecto bastante presente no repertório da Arte Contemporânea. Muitas vezes, a interação do espectador com o trabalho dá sentido à obra e a completa. Essa questão está presente tanto nas reflexões de Tassinari (2001) sobre Arte Contemporânea quanto nas reflexões sobre Arte Sonora apresentadas por Campesato (2007) e Iturbide (2017).

Campesato (2007) observa que, nas produções de Arte Sonora, a interação põe em contato o artista, a obra e o espectador. Tal interação começou com os Happenings e as Performances, experiências artísticas que surgiram nos anos 1960; implicavam uma situação em que o público era convidado "a participar de maneira mais ativa na produção de significados e sentidos da obra". (CAMPESATO, 2007, p. 123). Para Iturbide (2017), no caso da Arte Sonora, a interação entre o público e a obra pode acontecer em diferentes níveis. Algumas obras são totalmente abertas: sua finalização enquanto obra depende justamente da interação do espectador. Outras possuem uma estrutura autônoma e não dependem do público para se completarem. (ITURBIDE, 2017).

Um exemplo de interatividade nos trabalhos sonoros é a instalação Op_ERA Sonic Dimension (2005), das artistas Rejane Cantoni e Daniela Kutschat. ${ }^{10} \mathrm{~A}$ instalação consiste em três "paredes imaginárias" formadas por linhas digitais e verticais. As linhas lembram cordas musicais e podem ser acionadas pelo espectador, produzindo sons. Isso é possibilitado pela presença de sensores, os quais captam as ações do espectador e as transformam em diferentes sonoridades. O resultado é um ambiente sonoro inusitado e instigante.

\subsection{Aspectos Visuais}

As obras sonoras apresentam caráter diversificado. Não obstante, quase sempre revelam preocupação com o aspecto visual. Somente em casos excepcionais os artistas não atentam muito para esse aspecto; priorizam a tal ponto as possibilidades sonoras e o processo de escuta que deixam os aspectos visuais em segundo plano. De modo geral, todos se preocupam com a questão da visualidade do trabalho.

Os princípios da Gestalt ("estrutura" ou "forma", em alemão) nos ajudam a compreender os aspectos visuais implicados nas obras de Arte Sonora. Tendo por base tais princípios, o designer e professor João Gomes Filho propõe duas etapas para a leitura visual da forma. A primeira etapa implica os princípios de unidade (coerência entre as partes), segregação (contraste), fechamento (permite intuir a figura completa), continuidade ("fluidez visual"), proximidade (percepção enquanto conjunto), semelhança (elementos similares) e pregnância da forma (clareza). A segunda etapa envolve categorias conceituais fundamentais (harmonia, ordem, equilíbrio, simetria, contraste, cor, entre outras) e categorias que funcionam como técnicas visuais aplicadas (clareza, simplicidade, complexidade, profusão, coerência/incoerência, entre outras). O autor adverte, todavia, que a interpretação visual também depende do repertório cultural e da sensibilidade de cada indivíduo. (GOMES FILHO, 2009). Adiante, serão abordados os aspectos visuais de duas obras sonoras a partir desses princípios da Gestalt.

A instalação Forty Part Motet (Instituto Inhotim/Brasil, 2001), da artista canadense Janet Cardiff, apresenta uma plasticidade singela. ${ }^{11} \mathrm{~A}$ obra consiste em 40 alto-falantes dispostos em forma elíptica. Cada alto-falante reproduz o canto de um integrante do coral da Catedral de Salisbury, Inglaterra. Com uma organização simples e clara, a instalação apresenta unidade visual, conquistada pela repetição de elementos similares (princípio de similaridade, da Gestalt). Assim, a despeito do caráter singelo, o

\footnotetext{
${ }^{10}$ Ver: OBRA OP ERA - Sonic Dimension de Daniela Kutschat e Rejane Cantoni. 1 Vídeo (1'41"). Publicado por Daniela Kutschat, em 13 nov. 2014. Disponível em: https://vimeo.com/111771330. Acesso em: 26 maio 2019.

11 Ver: INSTITUTO INHOTIM. Janet Cardiff. Forty Part Moteto, 2001. Brumadinho/MG: Instituto Inhotim, [s.d]. Disponível em: https://www.inhotim.org.br/inhotim/arte-contemporanea/obras/forty-part-motet/. Acesso em: 12 jun. 2019.
} 
resultado visual é tão harmonioso quanto o canto-coral reproduzido pelos alto-falantes. Diferentemente disso, a obra Light Bearers (Montreal/Canadá, 2015), da dupla Maotik (Mathieu Le Sourd) e Etienne Paquette, apresenta um visual marcante. ${ }^{12} \mathrm{~A}$ instalação consiste em 2500 lâmpadas e hastes metálicas que se organizam como "plantas refletivas"; o trabalho evoca uma "floresta noturna". A partir da interação do espectador com tal "floresta", surgem aleatoriamente pequenas luzes como se fossem vagalumes. Além de ruídos de insetos reproduzidos no ambiente, outros sons também são gerados a partir do movimento do espectador. (MAOTIK, 2015). Visualmente, a composição é resolvida através dos princípios de proximidade e semelhança (princípios da Gestalt), o que proporciona unidade ao trabalho.

\subsection{Aspectos Sonoros}

A Arte Sonora utiliza o elemento sonoro como componente estético e essencial das obras. Para isso, tem utilizado novas tecnologias, novas possibilidades de gravação, de edição, de difusão e de incorporação do som. Tais tecnologias têm permitido, de igual modo, a interação do público e a possibilidade de que interfiram no resultado sonoro. (CAMPESATO, 2007; SAGARDUY, 2014).

No que se refere a essa mesma questão (sonoridade dos trabalhos), Iturbide (2017) ressalta que o artista deve observar alguns fatores importantes ao definir o aspecto sonoro de sua obra; um deles é a organização do som no tempo. Escreve o autor que a organização do som pode ocorrer de maneira simples e linear, ou pode apresentar um "fator surpresa". Este fator poderá manter o espectador durante mais tempo no ambiente da obra. Destaca também Iturbide (2017) a importância de proporcionar ao público uma movimentação pelo ambiente da obra; isso leva ao enriquecimento da percepção sonora. Para tanto, é interessante que o artista busque evidenciar as qualidades acústicas do espaço, sempre que possível.

A obra Jungle Jam (2006-2010) do coletivo Chelpa Ferro (Jorge Barrão, Luiz Zerbini e Sergio Mekler) ${ }^{13}$ talvez seja exemplo desse fator surpresa de que fala Iturbide (2017). A instalação consiste em sacos plásticos, presos a motores. Fixados às paredes do ambiente, os motores são também conectados a um computador e, quando acionados, fazem os sacos girarem e se chocarem contra as paredes. $O$ som produzido é singular e, de certo modo, inesperado. A rotação dos motores se desenvolve em uma sequência rítmica programada; tal sequência implica variações, todavia: 0 movimento dos sacos plásticos é sempre imprevisível e isso gera sonoridades "surpresa" no decorrer do tempo.

Outro aspecto relativo à sonoridade das obras é o uso ou não de alta tecnologia. (ITURBIDE, 2017). No caso da high technology, isso inclui desde softwares interativos a sensores; tais sensores, em geral, captam a presença do espectador e a transformam em estímulo sonoro. ${ }^{14}$

A sonoridade de uma obra também pode envolver a forma como se dá a difusão sonora pelo ambiente. Alguns artistas se dedicam a trabalhar este aspecto; investem no modo como o som se movimenta no espaço. Algumas obras propõem uma alteração na propagação do som através da movimentação das fontes sonoras (acionamento variado de alto-falantes, colocados em diferentes pontos do espaço, por exemplo). Essa movimentação do som proporciona ao espectador diferentes percepções. Em alguns casos, a movimentação pode ser do próprio espectador: sua aproximação ou afastamento das fontes sonoras resulta em diferentes percepções do som. (SAGARDUY, 2014). Um exemplo interessante dessa movimentação do som pelo espaço é a instalação Serpentinata 04 (Weimar, 2004), do arquiteto

\footnotetext{
12 Ver: LIGHT Bearers / Porteurs de Lumiere. 1 Vídeo (1'20”). Publicado por MAOTIK, em 11 ago. 2015. Disponível em: https://vimeo.com/136021336. Acesso em: 12 jun. 2019.

13 Ver: JUNGLE Jam. 1 Vídeo (4'15"). Publicado por chelpaferro, em 12 mar. 2009. Disponível em: https://www.youtube.com/watch?v=ebvwPJcrMb4. Acesso em: 02 jul. 2019.

${ }_{14}$ Como Light Bearers, de Maotik e Etienne Paquette e Op_ERA Sonic Dimension, de Rejane Cantoni e Daniela Kutschat, apresentadas anteriormente.
} 
e artista austríaco Bernhard Leitner. ${ }^{15} \mathrm{~A}$ obra é composta por tubos flexíveis de PVC, 40 alto-falantes, um amplificador e uma mesa de 40 canais. Configura-se como uma espécie de serpentina onde se instalam alto-falantes. A emissão sonora por cada alto-falante é programada de maneira alternada. Essa variação resulta numa espécie de "dança sonora" ao redor do espectador. Posicionado no interior da instalação, o espectador-ouvinte tem uma experiência fortemente sensorial. (SAGARDUY, 2014).

Ainda no que se refere à questão do som, outro aspecto é o que se denomina imagens sonoras, conceito discutido pela música eletroacústica. Segundo o músico e pesquisador Daniel Barreiro, as imagens sonoras podem ser compreendidas enquanto representações formadas na mente do espectador a partir dos estímulos sonoros. Barreiro (2010) observa que "as imagens sonoras são constantemente geradas na mente dos ouvintes com base nas características apresentadas pelos sons e na imaginação do ouvinte que 'completa' a cena musical apresentada pelos sons". (BARREIRO, 2010, p. 41). Um exemplo disso é a instalação Studies on Canvas (2004), do compositor e artista inglês Peter Batchelor. ${ }^{16} \mathrm{~A}$ instalação consiste em um painel branco, ausente de qualquer imagem. Atrás do painel estão posicionados 30 alto-falantes (grid 6x5) e que emitem sons aleatoriamente. Os sons emitidos pertencem ao cotidiano: sons de tempestades, de carros em movimento, de objetos rolando, de uma piscina de bolhas, entre outros. (BATCHELOR, 2007). Nesta instalação, o espectadorouvinte é estimulado a 'ver' as imagens sugeridas pelos sons. (BARREIRO, 2010).

\subsection{Tempo}

A questão do tempo na Arte Sonora diz respeito ao período em que o espectador fica envolvido com a obra; ou seja, depende do interesse despertado pelo trabalho. Neste caso, portanto, podemos dizer que o tempo da obra é o tempo de fruição pelo espectador. O tempo da obra, todavia, pode também depender exclusivamente da estrutura do trabalho; é o caso em que a obra possui um período de duração pré-definido e que independe do observador. (CAMPESATO, 2007; SAGUARDUY, 2004; ITURBIDE, 2017). Neste último caso, as obras exigem que o espectador aguarde, ouça e observe as transformações sonoras. (ITURBIDE, 2017). É o caso da obra Jungle Jam (2006-2010), do coletivo Chelpa Ferro. Neste trabalho, é necessário esperar o ciclo completo das rotações programadas para que se vivencie integralmente o "tempo" do trabalho.

Há casos, também, em que o tempo da obra é o tempo da natureza. É o que acontece na instalação Sonic Pavilion (2009), de Doug Aitken. ${ }^{17}$ Desenvolvida enquanto obra permanente do Instituto Inhotim (Brumadinho/MG), propõe aos visitantes que escutem os sons produzidos no interior do planeta. Para isso, instala microfones em um furo de 200 metros solo adentro. Os equipamentos de alta tecnologia captam o som da Terra e os reproduzem em tempo real no ambiente da instalação. Os sons emitidos nunca se repetem, pois dependem da movimentação espontânea dos componentes do solo.

\subsection{Tecnologia}

Em muitos casos, as produções de Arte Sonora revelam uma forte presença de tecnologias eletrônicas. Tais tecnologias têm representado novas possibilidades de criação. Têm potencializado também a mistura de linguagens, conceitos e definido o caráter híbrido das produções. (CAMPESATO, 2007; SAGARDUY, 2014).

Não é somente alta tecnologia o que tem sido usado pelas obras sonoras. A instalação Clinamen V4 (Bienal de Lyon, 2017), do artista francês Cèleste Boursier-Mougenot, por exemplo, utiliza tecnologia

15 Ver: LEITNER, Bernhard. Serpentinata 04. Bernhard Leitner. 2004. Disponível em: https://www.bernhardleitner.at/works. Acesso em: 08 jul. 2019.

${ }_{16}$ Ver: BATCHELOR, P. Studies on Canvas. Sonic Arts Network. Sound Circus Conference, jun. 2004. Disponível em: http://www.peterb.dmu.ac.uk/canvas.html. Acesso em: 09 jul. 2019.

17 Ver: INSTITUTO INHOTIM. Sonic Pavilion. [Doug Aitken, 2009]. Brumadinho/MG: Instituto Inhotim, [s.d]. Disponível em: https://www.inhotim.org.br/inhotim/arte-contemporanea/obras/sonic-pavilion/. Acesso em: 09 jul. 2019. 
simples e, mesmo assim, apresenta um resultado instigante. ${ }^{18}$ Equipamentos simples movimentam a água de uma grande piscina, onde flutuam tigelas de porcelana. As tigelas se chocam umas contra as outras em função da movimentação da água. As colisões geram sons aleatórios, suaves e que ressoam de modo harmonioso no ambiente. Outro exemplo de baixa tecnologia é o trabalho Giardino Sonoro (Sardenha, Itália), do escultor italiano Pinuccio Sciola (1942-2016). O artista produz sulcos em rochas de calcário, basalto e outros minerais, o que as transforma numa espécie de diapasões. Isso faz com que o deslizar dos dedos pelas rochas, ou a friç̧ão com um pedaço de pedra, resulte em sonoridades interessantes e singulares. ${ }^{19}$ Por outro lado, em muitos casos, o trabalho sonoro demanda uma tecnologia sofisticada. É o que acontece na instalação NASA Orbit Pavilion (East Coast, New York, 2015), do Studio KCA. O espaço futurista da instalação se assemelha a uma concha e permite que se escute, em tempo real, a sonificação da trajetória de satélites em órbita. ${ }^{20}$ Os painéis de alumínio que compõem a estrutura têm furos e simulam mais de 100 trajetórias orbitais dos satélites da NASA.

\subsection{Sensorialidade}

Como já foi dito, as produções artísticas contemporâneas apresentam um caráter fortemente sensorial. Provavelmente, isso decorre do fato de serem imersivas e, muitas vezes, interativas. Um exemplo disso é a Sonic Fountain (2013), do artista estadunidense Doug Aitken. O artista explora o espaço arquitetônico e acústico da 303 Gallery (New York). ${ }^{21}$ Propõe que se escutem os jatos de água emitidos por algumas válvulas e o gotejar de pingos d'água. A obra consiste em uma estrutura metálica com cinco válvulas controladas por computadores e uma cavidade circular escavada no piso da galeria. A cavidade é preenchida com um líquido esbranquiçado, formando uma espécie de poça d'água no ambiente expositivo. Alguns sons da instalação são previamente programados pelo artista, enquanto outros são produzidos a partir dos sons das gotas que incidem na poça. A instalação de Aitken proporciona aos espectadores uma experiência visual e auditivamente instigante.

\subsection{Significado}

Tanto a Arte Moderna quanto a Contemporânea são autônomas enquanto experiência estética, ou seja, valem por si só. Independem de significados previamente formulados e costumam estar sempre abertas a novas interpretações. De qualquer modo, torna-se interessante discutirmos algumas leituras provocadas pelo encontro com os trabalhos. Esta questão será considerada a partir do termo "significado".

Além do conteúdo estético, há diversos temas que tem sido tratados pelas obras sonoras: sustentabilidade, convívio social, responsabilidade, respeito pelas pessoas e pela natureza, etc. Entre as obras que conduzem a reflexões específicas, situa-se o trabalho Rio Oir (2011), do artista brasileiro Cildo Meireles. Traz considerações sobre questões ambientais. ${ }^{22}$ É um trabalho essencialmente sonoro e no qual o artista traz os sons de alguns rios brasileiros. Mescla estes sons com risadas, colhidas entre as comunidades ribeirinhas. Os sons são captados pelo artista e sua equipe ao longo de um

\footnotetext{
18 Ver: 14e BIENNALE de Lyon : rencontre avec Céleste Boursier Mougenot. 1 Vídeo (3'14"). Publicado por Biennale de Lyon, em 2 out. 2017. Disponível em: https://www.youtube.com/watch?v=hpAC7CfhCNs. Acesso em: 18 set. 2018.

${ }^{19}$ Ver: TRE MINUTI D'ARTE. II Giardino di Sciola. [II Giardino Sonoro di Sciola con Maria Sciola]. 1 Vídeo (4'32"). Publicado por La Donna Sarda, em 6 set. 2015. Disponível em: https://www.youtube.com/watch?v=NSLql4szfc4\&t=144s. Acesso em: 09 maio 2019.

20 Ver: STUDIO KCA. NASA Orbit Pavilion (East Coast). New York: 2015. Disponível em: http://www.studiokca.com/projects/nasa-orbit-pavilion-east-coast/. Acesso em: 25 set. 2018.

${ }^{21}$ A instalação é parte integrante, e central, da exposição individual 100YRS de Aitken. Ver: DOUG Aitken - Sonic Fountain / 303 Gallery 2013. 1 Vídeo (1'00”). Publicado por Doug Aitken Workshop, em 30 jan. 2013. Disponível em: https://vimeo.com/58588714. Acesso em: 03 ago. 2018.

${ }_{22}$ Ver: INSTITUTO ITAÚ CULTURAL. Ocupação Cildo Meireles. Curadoria: Guilherme Wisnik. São Paulo: Instituto Itaú Cultural, 2011. Disponível em: https://www.itaucultural.org.br/ocupacao/cildo-meireles/. Acesso em: 05 set. 2018.
} 
percurso pelo interior do Brasil. Além da questão estética, Rio Oir traz para o debate, do mesmo modo que grande parte da produção artística contemporânea, temas como ética, responsabilidade social e preocupação com a natureza. São assuntos atuais, importantes, sugeridos enquanto discussão tanto a adultos, crianças e adolescentes.

Outro trabalho que abre possibilidades para discussões interessantes é o Animas River Sound Sculpture (2017), de Brian House..$^{23} \mathrm{O}$ objetivo do trabalho é a percepção do som emitido por placas metálicas. O interesse estético disso liga-se, por sua vez, a uma questão ambiental. A intensidade dos sons emitidos varia em função do grau de poluição dos rios. A obra consiste em quatro painéis metálicos (ferro oxidado, alumínio, cobre e chumbo), ligados a sensores. Tais sensores captam o teor de metal do rio Animas, no Colorado (EUA) e fazem vibrar as placas conforme a informação transmitida. Isso resulta em diferentes sonoridades, produzidas no ambiente da galeria.

Rio Oir e Animas River Sound Sculpture são exemplos de trabalhos cuja percepção estética tem sido enriquecida pela discussão dos vários significados das obras. Tanto num caso quanto no outro, a propósito, a discussão dos sentidos (significados) destes trabalhos pode ser auxiliada pela mediação cultural. Trata-se de uma prática constante nas instituições de Arte, atualmente. Visa aproximar a obra de arte do público em geral e, em especial, das crianças e dos jovens. É eficiente no sentido de abrir o debate a respeito das várias leituras, percepções e significados acionados pelas obras.

Referência no assunto, a educadora e pesquisadora em arte/educação Ana Mae Barbosa ressalta que a mediação cultural tem sido importante não somente no sentido de conectar as pessoas com a arte, mas, através disso, de conectar as pessoas com o próprio mundo. Segundo Barbosa (2009), através da arte refinamos nossa sensibilidade e percepção acerca do ambiente que nos cerca. Assim, melhoramos a compreensão não apenas de nós mesmos, mas também do outro. Isto contribui para melhorar as relações humanas. (BARBOSA, 2009).

\section{Análise das obras}

As obras selecionadas foram analisadas a partir dos seguintes aspectos: espacialidade, interatividade, aspectos visuais, aspectos sonoros, tempo, tecnologia, sensorialidade e significado.

No que se refere à espacialidade, foi considerado se a obra é bidimensional, tridimensional ou ambiental. Consideramos bidimensional a obra que privilegia a visada frontal; tridimensional a que exige que o espectador circule em torno da obra; tratamos como ambiental aquela que se configura como um ambiente e que permite que o espectador entre em sua espacialidade.

O aspecto interatividade foi analisado quanto ao grau de envolvimento do público com a obra e foi observado em três níveis: consideramos se a obra propõe apenas a contemplação 'estática', se provoca algum deslocamento do corpo (para ser percebida) ou se necessita da manipulação do espectador (para se completar enquanto obra).

Os aspectos visuais foram analisados a partir dos princípios da Gestalt. Buscamos também compreender se $o$ artista levou em conta os aspectos visuais da obra e se se preocupou com questões como harmonia, equilíbrio, clareza, simplicidade, etc.

Os aspectos sonoros foram analisados quanto ao caráter do som: acústico/digital, grave/agudo ${ }^{24}$ e sua intensidade ${ }^{25}$. Analisamos também se o som é musical ou não, se existe um padrão rítmico ou não, etc.

23 TWMW - Those Who Make Waves. Animas River Sound Sculpture. [Brian House, 2017]. Disponível em: http://www.thosewhomakewaves.com/home/2017/5/4/animas-river-sound-sculpture. Acesso em: 31 maio 2018.

${ }^{24} \mathrm{Na}$ Música, o termo registro é utilizado na diferenciação entre o som grave e o agudo.

${ }^{25} \mathrm{Na}$ Música, o termo intensidade é utilizado para definir se o som é mais forte ou mais fraco, ou seja, mais ou menos audível. 
Quanto à questão tempo, buscamos saber se a obra se desenvolve em um período pré-determinado, ou se o tempo da obra está relacionado com a interação do espectador.

A análise do aspecto tecnologia considerou o grau tecnológico da obra: baixo ou de alta tecnologia.

No que se refere ao aspecto sensorialidade, observamos quais sentidos, além da audição, são ativados pela obra: tato, sistema vestibular (relacionado ao equilíbrio do corpo) e/ou proprioceptivo (relacionado à noção de localização, posição e orientação do corpo no espaço).

Quanto à questão do significado da obra, ressaltamos que depende da interpretação de cada um. Existem obras que tornam explícito um tema específico e estimulam reflexões e debates. Outras são mais abstratas ou não evidenciam, além da questão estética, determinados temas ou assuntos. No que tange ao aspecto significado, é importante sublinhar, de qualquer modo, que a mediação cultural ${ }^{26}$ é sempre importante; enriquece a percepção das pessoas sobre o trabalho e permite trocas entre as várias percepções.

\subsection{Análise da obra Lines (2016) de Anders Lind}

$\mathrm{Na}$ instalação sonora Lines (2016), o compositor sueco Anders Lind utiliza dispositivos que captam os movimentos, as ações dos espectadores e os transformam em diferentes sons. ${ }^{27} \mathrm{~A}$ instalação apresenta linhas coloridas em paredes e pisos, além de tubos suspensos do teto. Lines se apropria das superfícies do espaço, portanto, e se configura como um conjunto de "instrumentos musicais" não convencionais. ${ }^{28}$ A propósito, as cinco linhas horizontais dispotas nas paredes lembram um pentagrama musical (utilizado na música para registrar as notas e figuras musicais). Instalados no piso, os sensores captam a presença da mão do espectador junto às linhas horizontais. A movimentação da mão do espectador, junto às linhas, proporciona a emissão de diferentes sons musicais. A interação com os quinze tubos coloridos também resulta na emissão de sons, a depender dos movimentos do observador e da distância a que está dos tubos. A movimentação do visitante também provoca mudanças nas características do som: ritmo, altura, intensidade, timbre, entre outras. No piso, estão fixadas dez linhas coloridas. Para cada uma delas há um sensor. A movimentação do espectador em relação a estas linhas resulta numa emissão sonora com ritmo mais lento ou mais rápido. E, se o espectador passa de uma linha para outra, há uma variação na altura do som emitido; ou seja, o som se torna mais grave ou mais agudo.

Quanto à espacialidade, Lines é ambiental: configura um ambiente onde o espectador entra. A propósito, o ambiente se divide em três setores. O primeiro corresponde ao espaço que abriga as cinco linhas fixadas na parede. O segundo corresponde ao espaço com as dez linhas fixadas no piso. Por último, o espaço central é onde estão os quinze tubos que pendem do teto.

No que se refere à interatividade, trata-se de um trabalho que demanda ativamente a participação do público. Depende desta interação para se completar enquanto obra. $O$ deslocamento e a movimentação do corpo do espectador ativam os dispositivos que transformam os movimentos do público em sons.

Ainda que Lines seja uma instalação essencialmente sonora, revela alguns cuidados quanto à questão visual. Há ordem e regularidade na disposição dos elementos coloridos (linhas e tubos). As mesmas cores se repetem em cada espaço. Outras repetições acontecem: as linhas retas nas paredes e piso, o espaçamento uniforme entre as linhas, bem como a espessura idêntica dos tubos. Tais repetições se

\footnotetext{
${ }^{26}$ Trata-se da ação de agentes culturais e educadores no sentido de colocar a obra em discussão.

${ }^{27}$ Ver: LINES - an Interactive Sound Art Exhibition. 1 Vídeo (6'08”). Publicado por VoicesOfU, em 8 dez. 2016. Disponível em: https://www.youtube.com/watch?v=hP36xoPXDnM. Acesso em: 13 jul. 2018.

${ }^{28} \mathrm{~A}$ obra de Anders Lind foi exposta em diferentes países, esta análise se refere à instalação no Västerbottens Museum, em Umeå/Suécia (2016).
} 
enquadram no princípio de similaridade da Gestalt. Isso tudo confere ritmo, unidade, harmonia e equilíbrio visual ao trabalho.

Quanto à sonoridade, a instalação envolve a produção de sons digitais: os estimulos recebidos pelos sensores são lidos por um computador e transformados em sons. Esses sons podem apresentar maior ou menor intensidade, assim como uma variação no ritmo, na altura, no timbre, etc.

A questão tempo, em Lines, concerne ao período em que o espectador interage com o trabalho. Isso depende, é claro, do interesse e do envolvimento de cada visitante. O tempo de fruição da obra depende, ainda, da natureza da interação: se individual ou coletiva. ${ }^{29}$

No que se refere à tecnologia, Lines demanda recursos altamente tecnológicos para a produção dos sons. Tais recursos envolvem a utilização de sensores, computadores e software para a captação, leitura e transformação dos estímulos em sonoridades.

A sensorialidade se apresenta de maneira marcante na instalação. Além da audição, o trabalho aciona outros sentidos no espectador: visão, sistema vestibular (sensação de equilíbrio) e sistema proprioceptivo (o responsável pela sensação de localização no espaço). O equilíbrio é necessário na interação com a instalação, isso porque é necessário equilíbrio na passagem de uma linha para outra e no movimento de se abaixar e de se erguer sob os tubos. Já o sistema proprioceptivo é ativado a partir da aproximação ou distanciamento do corpo com relação aos sensores.

A instalação Lines é uma obra instigante e que possibilita a produção de sons melodiosos através de um instrumento não convencional: a própria obra. Ressaltamos, entretanto, que os possíveis significados do trabalho dependerão da percepção de cada um. Destacamos também que a mediação poderá ser interessante para ativar diferentes reflexões e leituras. Uma dessas reflexões pode ser o quanto o ritmo e a velocidade dos sons interferem nas emoções e provocam agitação, tranquilidade, alegria, tristeza, etc.

Em síntese, Lines é uma proposta sensível, altamente interativa e que incentiva a participação através da movimentação do corpo. Proporciona uma rica experiência sensorial ao público de todas as idades. Em síntese, a experiência com a obra pode estimular os sentidos, provocar a movimentação do corpo, ativar o equilíbrio, apurar a audição e ampliar o repertório estético e cultural.

\subsection{Análise da obra Oasi (2014) de Licia Galizia e Michelangelo Lupone}

Oasi (2014) é uma instalação sonora idealizada especialmente para o espaço sensorial do Museu de Arte Contemporânea de Roma (MACRO). ${ }^{30}$ Resultado da parceria entre a escultora italiana Licia Galizia e o compositor e pesquisador Michelangelo Lupone, o trabalho é interativo: sons são produzidos quando o espectador desliza sua mão pelas superfícies curvas da obra. Lisas de um lado, tais superfícies têm ranhuras no lado oposto. Conforme o toque do espectador, as chapas poderão vibrar com timbres diversos, diferentes alturas e com maior ou menor intensidade. (OASI, 2017, vídeo). 31

O ambiente também possui piso inclinado, o que provoca balanço e vibração nas superfícies e ativa ainda mais a interação com o trabalho. Outro aspecto é o caráter intimista e acolhedor do ambiente

\footnotetext{
${ }^{29}$ A instalação oferece ainda a possibilidade de performances realizadas pelos artistas, os quais "compõem" ou "improvisam" a partir de sua interação com os sensores. Neste caso, a obra adquire um aspecto contemplativo e o tempo da obra está condicionado ao tempo da performance realizada.

30 Ver: GALIZIA/LUPONE @ MACRO - OASI Adaptive sculptural-musical installation. 1 Vídeo (1'41"). Publicado por CRM Centro Ricerche Musicali, em 07 jul. 2014. Disponível em: https://www.youtube.com/watch?v=4EmUoXvGxSE. Acesso em: 19 set. 2018.

31 Ver: OASI, 2017. 1 Vídeo (12’08”). Publicado por Mister Wolf s.r.l., em 12 out. 2018. Disponível em: https://youtu.be/PquTbvl57Og. Acesso em: 03 maio 2019.
} 
criado. As superfícies (de tonalidade cinza claro) são instaladas em dois ambientes escuros e contíguos. Um feixe de luz gera um ambiente aconchegante e que aproxima o espectador da obra.

Além da audição e da visão, Oasi ativa os sentidos vestibular e proprioceptivo uma vez que demanda o movimento e o equilíbrio do corpo. Outro aspecto é que que, em virtude de implicar fortemente a questão tátil, acolhe pessoas com deficiência visual. Aliás, essa era uma das solicitações da MACRO: construir um ambiente permanente e que também fosse acessível a pessoas com problemas visuais.

A tecnologia utilizada na instalação utiliza "planofones" (planofoni, em italiano), superfícies estruturadas com sensores. Os sensores, por sua vez, se conectam diretamente a um computador. Tais "planofones" são resultado de uma pesquisa desenvolvida pelos compositores Michelandelo Lupone e Laura Bianchini, fundadores do Centro de Pesquisa Musical de Roma (Centro Ricerche Musicali di Roma). A pesquisa destes compositores, aliás, envolve uma investigação sobre a qualidade e as formas do som, bem como sobre o controle de sua difusão no espaço. (CRM, 2009).

No que se refere à espacialidade, Oasi é uma obra ambiental e também tem caráter escultórico. Isso é devido à forte plasticidade das placas curvas.

No que diz respeito aos aspectos visuais, é uma obra que possui uma estética marcante. Com base no princípio da similiaridade (Gestalt), o trabalho apresenta unidade visual conferida pela repetição de elementos semelhantes: as várias superfícies curvas. $O$ feixe de luz direcionado a esses elementos proporciona, por sua vez, um instigante contraste de luz e sombra. As paredes e os pisos escuros destacam as superfícies claras e as curvas imprimem uma ideia de movimento, além de convidarem à interação do visitante.

Como foi dito, os aspectos sonoros de Oasi dependem da leitura do computador que está conectado ao trabalho. Este interpreta os toques e os movimentos dos visitantes e os transforma em sons digitais. O resultado vai depender da qualidade da ação de cada visitante: intensidade, velocidade do toque, etc.

A questão tempo, em Oasi, está relacionada ao interesse do visitante; fica em função do entusiasmo para experimentar a obra. O tempo está relacionado, portanto, ao período de fruição do trabalho.

Quanto ao aspecto tecnologia, Oasi utiliza recorre à alta tecnologia. Mas outros aspectos tecnológicos a serem considerados são, também, a montagem do ambiente e a confecção das superfícies escultóricas (criação de Licia Galizia).

A instalação se apresenta, enfim, como uma obra aberta e musical. Fortemente sensorial, contribui para tomarmos consciência acerca do nosso próprio corpo e de sua relação com o espaço. A interação com Oasi pode também acontecer de olhos fechados (ou vendados); isso ativa mais fortemente os sentidos do tato e da audição; trata-se de uma situação, aliás, vivenciada por pessoas com limitação visual. Neste sentido, pode nos ajudar a pensar sobre questões de acessibilidade e percepção limitada. De qualquer forma, a mediação cultural pode contribuir para a troca de outras percepções e leituras sobre a obra.

Em síntese, observamos que Oasi é uma proposta sensível e interessante, tanto do ponto de vista sonoro quanto plástico. Altamente interativa, convida o público para uma participação espontânea, intuitiva, dinâmica e, deste modo, proporciona uma vivência multisensorial e instigante aos espectadores de todas as idades. 


\subsection{Análise da obra 329 Prepared Dc-Motors, Cotton Balls, Toluene Tank (2013) de Zimoun}

329 Prepared Dc-Motors, Cotton Balls, Toluene Tank (Dottikon, Suíça, 2013) é a primeira instalação permanente do artista suiço Zimoun. Como em outras obras do artista, o título não é nada além do que a descrição dos materiais utilizados. O objetivo do trabalho é oferecer a experiência acústica produzida pelo choque de 329 pequenas esferas de algodão contra a parede metálica de um antigo tanque. A obra é composta por motores de corrente contínua, esferas de algodão compactado e fios de arame, entre outros materiais. Ocupa um tanque desativado de tolueno, construído na década de 1950, com 9,40 metros de diâmetro e 12,80 metros de altura. ${ }^{32}$

O tanque foi transportado do seu local original e assentado em uma base de concreto. Tal base também serve de banco, no interior do espaço. Além da mudança de local, o tanque recebeu pintura interna branca, sistema de iluminação e ventilação. Uma porta foi aberta para possibilitar o acesso ao interior da instalação.

Como foi dito, o efeito sonoro consiste no choque das esferas de algodão contra a superfície interna do tanque. Para conseguir este efeito, Zimoun fixou cada uma das esferas de algodão na ponta de um arame. Sob a ação de pequenos motores, os arames se movimentam e provocam o choque das esferas contra a parede do tanque. A fim de alcançar uma variedade no comportamento de cada conjunto (motor-arame- esfera de algodão) e a consequente variação no efeito sonoro, Zimoun definiu medidas aleatórias e dobras diferentes para cada arame. (ZIMOUN, 2016).

No que se refere à espacialidade, a instalação 329 [...] é ambiental: o próprio tanque se configura como suporte da obra. A distribuição dos elementos (motor/arame/esfera de algodão) em toda a superfície cilíndrica produz um efeito sonoro envolvente e imersivo.

Com relação ao aspecto interatividade, tem-se tanto contemplação quanto o deslocamento do espectador pelo ambiente. Isso é necessário para que o espectador possa perceber os diferentes efeitos sonoros. No centro do tanque, por exemplo, a percepção sonora é distinta do que a que se obtém mais próximo à parede da instalação.

Quanto aos aspectos visuais, Zimoun recorre aos princípios de similaridade e de proximidade, discutidos pela teoria da Gestalt. Os elementos (motor/arame/esfera de algodão) são idênticos e colocados de modo equidistante uns dos outros. Isso confere forte unidade visual ao conjunto. Aliada à pintura branca e à luz intensa, a delicadeza desses conjuntos confere ao ambiente um caráter instigante e, ao mesmo tempo, leve.

Os aspectos sonoros decorrem do encontro das esferas de algodão com a parede do tanque. Resultam também do ruído dos motores e da movimentação dos arames. Os sons emitidos são constantes; dependem da potência dos motores e, como já foi observado, da medida dos arames. ${ }^{33}$

Quanto ao aspecto tempo, decorre do período em que as pessoas permanecem na instalação. Sensores detectam a presença do público e acionam os motores. Quando todos saem, os motores param. O tempo da obra é, portanto, o tempo de sua fruição pelas pessoas.

\footnotetext{
32 Ver: «329 PREPARED dc-motors, cotton balls, toluene tank | Zimoun 2013» Making-of Video by Florian Buerki. 1 Vídeo (7'26"). Publicado por Zimoun, em 30 maio 2013. Disponível em: https://vimeo.com/67285859. Acesso em: 03 abr. 2019.

${ }^{33}$ A percepção sonora do espectador varia de acordo com sua localização no espaço da instalação. Mais próximo da parede, os sons produzidos pelas unidades próximas são percebidos mais intensamente e os sons produzidos pelo conjunto todo são percebidos "ao fundo".
} 
Com relação à tecnologia, a instalação é composta por elementos simples e de baixa complexidade tecnológica: motores de corrente contínua (3V) e arames, ligados a pequenas esferas de algodão compactado.

No que se refere à sensorialidade, a experiência estimula tanto a visão quanto a audição. O sistema vestibular (equilíbrio) é ativado pelo deslocamento do visitante pelo ambiente; já o proprioceptivo (noção de posição no espaço) é acionado pelo seu posicionamento no interior da instalação. Neste sentido, podemos dizer que a instalação proporciona uma experiência multissensorial.

A instalação permanente de Zimoun apresenta um caráter abstrato e que permite diferentes percepções e interpretações. Experiência sonora e imersiva, ordenada e ao mesmo tempo imprevisível, pode nos levar a refletir sobre a ordem e o caos, por exemplo. Pode também remeter a sons de fenômenos naturais, como chuva. É claro que isso depende da interpretação de cada espectador-ouvinte. Contudo, se o tema chuva vier à tona, algumas discussões podem ser abertas com relação a isso: sua importância em nosso processo vital, nossa vivência com esse fenômeno natural, etc. Toda essa discussão poderá ser facilitada, por outro lado, pelos mediadores culturais.

Em síntese, 329 Prepared Dc-Motors, Cotton Balls, Toluene Tank (2013) é uma proposta sensível. Instalação singular e instigante, tanto nos aspectos visuais quanto sonoros, também proporciona uma experiência fortemente sensorial a pessoas de todas as idades. Cria um ambiente sonoro envolvente e pode gerar diferentes conexões simbólicas e interpretações. A partir de suas vivênvias e memórias, cada individuo reage à sua maneira no contato com a obra. A experiência amplia o nosso repertório cultural e possibilita diversas discussões.

\section{Considerações Finais}

O estudo conclui com a percepção de que a Arte Sonora é uma experiência contemporânea bastante diversificada e de que possui uma interface com a Música, a Arquitetura e as Artes Visuais. Além disso, constata que possui um caráter fortemente sensorial, quase sempre. Como muitos outros trabalhos de Arte Contemporânea, ademais, configura-se enquanto instalação diversas vezes.

Como foi observado, a abordagem de vários casos de Arte Sonora, aqui analisados, aponta para o caráter quase arquitetônico dos trabalhos. Isso decorre do fato de que vários se configuram enquanto ambientes. Foi por conta deste caráter espacial, aliás, que certas considerações de alguns críticos da Arquitetura (TUAN, 1983; ZEVI, 2009 e PALLASMAA, 2011) puderam ser aproveitadas para a abordagem das obras. Entre tais considerações, está a questão da sensorialidade envolvida em toda experiência espacial.

O contato com as obras sonoras revelou, também, que a participação do público é algo fundamental em muitas delas. Várias dessas obras somente se completam a partir da interação do espectador. Além disso, o estudo mostrou que muitos trabalhos sonoros apresentam uma visualidade marcante. De modo geral, a preocupação com o interesse visual está presente em todas as obras.

Com relação aos aspectos sonoros, muitas obras se apropriam de sons do cotidiano, outras de sons da natureza. Em alguns casos, os sons são processados e se misturam a sons digitalizados. Há, ainda, aquelas cujos sons são produzidos a partir de equipamentos mecânicos ou objetos ativados em tempo real. No que se refere a esses recursos tecnológicos, a propósito, variam de acordo com os investimentos. Muitas vezes, envolvem tecnologia mais simples; outras vezes, alta tecnologia. De qualquer modo, o interesse das obras analisadas fica mais em função do caráter instigante da obra do que de seu nível tecnológico.

A questão tempo também foi um aspecto investigado. Alguns trabalhos apresentam uma estrutura temporal pré-determinada. Outras apresentam um ciclo temporal, como a instalação Jungle Jam (2006- 
2010) de Chelpa Ferro. Há ainda aquelas que dependem do envolvimento do espectador; nestes casos, o tempo da obra é o tempo da fruição do visitante.

No que se refere à dimensão sensorial dos trabalhos, analisamos quais sentidos a obra ativa no público. Além de acionarem os sentidos da audição e da visão, algumas propostas também estimulam o tato. Outras envolvem o sistema vestibular (equilíbrio) e o sistema proprioceptivo (noção da posição no espaço); isso é porque demandam o deslocamento do espectador pelo ambiente da obra.

Embora toda obra de arte valha por si só enquanto experiência estética sensível, foram indagados algumas questões e significados deixados em aberto pela obra. Verificamos que muitos trabalhos nos fazem refletir sobre temas específicos, como preservação do meio ambiente, por exemplo. Consideramos, também, que, dentro da questão do significado da obra, o papel do mediador cultural é importante; é ele quem promove debates a partir das percepções do próprio espectador. Por vezes, essa mediação cultural pode ser realizada pelo próprio artista.

Por fim, diríamos que o presente estudo e análise de obras sonoras gerou perspectivas futuras de aprofundamento. Esperamos que as considerações aqui apresentadas estimulem outras pessoas (talvez arquitetos e agentes culturais, ou os próprios artistas) a refletirem sobre a valiosa contribuição da Arte Sonora enquanto forma sensível e que promove interessantes trocas de experiências e de percepções.

\section{Referências}

«329 PREPARED dc-motors, cotton balls, toluene tank | Zimoun 2013» Making-of Video by Florian Buerki. 1 Vídeo (7'26"). Publicado por Zimoun, em 30 maio 2013. Disponível em: https://vimeo.com/67285859. Acesso em: 03 abr. 2019.

14e BIENNALE de Lyon : rencontre avec Céleste Boursier Mougenot. 1 Vídeo (3'14"). Publicado por Biennale de Lyon, em 2 out. 2017. Disponível em: https://www.youtube.com/watch?v=hpAC7CfhCNs. Acesso em: 18 set. 2018.

ANDERS Lind. Disponível em: http://www.soundslikelind.se/. Acesso em: 07 jul. 2018.

BARBOSA, Ana Mae. Mediação cultural é social. In: BARBOSA, Ana Mae; COUTINHO, Rejane Galvão. (Org.). Arte/Educação como mediação cultural e social. São Paulo: UNESP, 2009, p. 13-22.

BARREIRO, D. Sonic Image and Acousmatic Listening. Organised Sound. Cambridge University Press, v. 15, n. 01, p. 35-42, 2010. Disponível em: https://www.cambridge.org/core/journals/organisedsound/article/sonic-image-and-acousmatic-listening/EF376C1E37428B29009E20C23807345F. Acesso em: 18 fev. 2019.

BATCHELOR, P. Really Hearing the Thing: An Investigation of the Creative Possibilities of Trompe L'Oreille and the Fabrication of Aural Landscapes. EMS: Electroacoustic Music Studies Network. Inglaterra: De Montfort University, Leicester, 2007. Disponível em: http://www.emsnetwork.org/IMG/pdf BatchelorEMS07.pdf. Acesso em: 09 jul. 2019.

BATCHELOR, P. Studies on Canvas. Sonic Arts Network. Sound Circus Conference, jun. 2004. Disponível em: http://www.peterb.dmu.ac.uk/canvas.html. Acesso em: 09 jul. 2019.

CAMPESATO, Lílian. Arte Sonora. Metamorfose das Musas. 2007. Dissertação (Mestrado em Artes) Escola de Comunicações e Artes da Universidade de São Paulo. São Paulo, 2007. Disponível em: http://www.teses.usp.br/teses/disponiveis/27/27157/tde-17062008-152641/publico/dissertacao.pdf. Acesso em: 08 maio 2018.

CHION, Michel. Guide to Sound Objects. Pierre Schaeffer and Musical Research. English translation by John Dack and Christine North. London, 2009, p.30-33. Disponível em: http://www.ears.dmu.ac.uk/spip.php?page=articleEars\&id_article=3597. Acesso em: 05 fev. 2019.

CRM - Centro Ricerche Musicali. Planofoni. In: CRM - Centro Ricerche Musicali. Roma, 30 Giugno 2009. Disponível em: http://www.crm- 
music.it/index.php?option=com content\&view=article\&id=53\%3Aplanofoni\&catid=99\%3Aplanofoni\&lte mid=139\&lang=it. Acesso em: 07 maio 2019.

DOUG Aitken - Sonic Fountain / 303 Gallery 2013. 1 Vídeo (1'00"). Publicado por Doug Aitken Workshop, em 30 jan. 2013. Disponível em: https://vimeo.com/58588714. Acesso em: 03 ago. 2018.

FOSTER, Hal. A escultura refeita. In: O Complexo Arte-Arquitetura. Tradução de Célia Euvaldo. São Paulo: Ubu Editora, 2017. p. 159-195.

GALIZIA, L. Opere Adattive Sultoreo-Musicali. Licia Galizia. Scritti. [S.I.], 2018. Disponível em: https://liciagalizia.it/scritti/opere-adattive-scultoreo-musicali/\#italian. Acesso em: 15 mar. 2019.

GALIZIA/LUPONE @ MACRO - OASI Adaptive sculptural-musical installation. 1 Vídeo (1'41"). Publicado por CRM Centro Ricerche Musicali, em 07 jul. 2014. Disponível em: https://www.youtube.com/watch?v=4EmUoXvGxSE. Acesso em: 19 set. 2018.

GOMES FILHO, J. Gestalt do objeto: sistema de leitura visual da forma. São Paulo: Escrituras, 2009.

INSTITUTO INHOTIM. Forty Part Moteto. [Janet Cardiff, 2001]. Brumadinho/MG: Instituto Inhotim, [s.d]. Disponível em: https://www.inhotim.org.br/inhotim/arte-contemporanea/obras/forty-part-motet/. Acesso em: 12 jun. 2019.

INSTITUTO INHOTIM. Sonic Pavilion. [Doug Aitken, 2009]. Brumadinho/MG: Instituto Inhotim, [s.d]. Disponível em: https://www.inhotim.org.br/inhotim/arte-contemporanea/obras/sonic-pavilion/. Acesso em: 09 jul. 2019.

INSTITUTO ITAÚ CULTURAL. Ocupação Cildo Meireles. Curadoria: Guilherme Wisnik. São Paulo: Instituto Itaú Cultural, 2011. Disponível em: https://www.itaucultural.org.br/ocupacao/cildo-meireles/. Acesso em: 05 set. 2018.

ITURBIDE, Manuel R. La expansión de la escultura y de la instalación sonora en el arte (1). SulPonticello. Revista online de música y arte sonoro. N. 38, may 2017. Sección Fuera de Tono. Não paginado. ISSN 1697-6886. Disponível em: http://www.sulponticello.com/la-expansion-de-la-esculturay-de-la-instalacion-sonora-en-el-arte-1/. Acesso em: 07 fev. 2019.

ITURBIDE, Manuel R. La expansión de la escultura y de la instalación sonora en el arte (2). SulPonticello. Revista online de música y arte sonoro. N. 39, june 2017. Sección Fuera de Tono. Não paginado. ISSN 1697-6886. Disponível em: http://www.sulponticello.com/la-expansion-de-la-esculturay-de-la-instalacion-sonora-en-el-arte-2/. Acesso em: 07 fev. 2019.

JUNGLE Jam. 1 Vídeo (4'15"). Publicado por chelpaferro, em 12 mar. 2009. Disponível em: https://www.youtube.com/watch?v=ebvwPJcrMb4. Acesso em: 02 jul. 2019.

KRAUSS, Rosalind. A escultura no campo ampliado. Tradução de Elizabeth Carbone Baez. Revista Arte \& Ensaios: revista do Programa de Pós-Graduação em Artes Visuais da Escola de Belas Artes da UFRJ, Rio de Janeiro, n. 17, p. 128-137, 2008. Disponível em: https://www.ppgav.eba.ufrj.br/wpcontent/uploads/2012/01/ae17_Rosalind_Krauss.pdf. Acesso em: 01 nov. 2017.

KWON, Miwon. One place after another: site-specific art and locational identity. Cambridge: MIT, 2002.

LEITNER, Bernhard. Serpentinata 04. Bernhard Leitner. 2004. Disponível em: https://www.bernhardleitner.at/works. Acesso em: 08 jul. 2019.

LICIA Galizia. Disponível em: https://liciagalizia.it/. Acesso em: 19 set. 2018.

LIGHT Bearers / Porteurs de Lumiere. 1 Vídeo (1'20"). Publicado por MAOTIK, em 11 ago. 2015. Disponível em: https://vimeo.com/136021336. Acesso em: 12 jun. 2019.

LINES - an Interactive Sound Art Exhibition. 1 Vídeo (6'08"). Publicado por VoicesOfU, em 8 dez. 2016. Disponível em: https://www.youtube.com/watch?v=hP36xoPXDnM. Acesso em: 13 jul. 2018.

MAOTIK. When nature comes to life in na industrial environment. In: MAOTIK. Projects. Light Bearers. Canada, 2015. Disponível em: http://www.maotik.com/lightbearers/. Acesso em: 12 jun. 2019. 
OASI, 2017. 1 Vídeo (12'08”). Publicado por Mister Wolf s.r.l., em 12 out. 2018. Disponível em: https://youtu.be/PquTbvl57Og. Acesso em: 03 maio 2019.

OBRA OP ERA - Sonic Dimension de Daniela Kutschat e Rejane Cantoni. 1 Vídeo (1'41"). Publicado por Daniela Kutschat, em 13 nov. 2014. Disponível em: https://vimeo.com/111771330. Acesso em: 26 maio 2019.

OLAFUR Eliasson. Artwork. Disponível em: https://olafureliasson.net/archive/artwork. Acesso em 07 jun. 2019.

PALLASMAA, Juhani. Os olhos da pele: a arquitetura e os sentidos. Tradução de Alexandre Salvaterra. Porto Alegre: Bookman, 2011.

SAGARDUY, Mikel A. El espacio y la dimension del sonido. Una observación desde la experimentación artística. 2014. Tesis (Doctorado) - Facultad de Bellas Artes, Departamento de Arte y Tecnología, Universidad del Pais Vasco, 2014. Disponível em: https://www.researchgate.net/publication/303543435 El espacio y la dimension del sonido Una ob servacion_desde la_experimentacion_artistica. Acesso em: 15 fev. 2019.

SESC_VIDEOBRASIL. Olafur Eliasson: Seu Corpo da Obra. 17ำ Festival Internacional de Arte Contemporânea. Panoramas do Sul. [Catálogo de Exposição]. São Paulo: Sesc_VideoBrasil, 2011.

STUDIO KCA. NASA Orbit Pavilion (East Coast). New York: 2015. Disponível em: http://www.studiokca.com/projects/nasa-orbit-pavilion-east-coast/. Acesso em: 25 set. 2018.

TASSINARI, Alberto. O espaço moderno. São Paulo: Cosac Naify Edições, 2001.

TRE MINUTI D'ARTE. II Giardino di Sciola. [II Giardino Sonoro di Sciola con Maria Sciola]. 1 Vídeo (4'32"). Publicado por La Donna Sarda, em 6 set. 2015. Disponível em: https://www.youtube.com/watch?v=NSLql4szfc4\&t=144s. Acesso em: 09 maio 2019.

TUAN, Yi-Fu. Espaço e Lugar. A Perspectiva da Experiência. Tradução de Lívia de Oliveira. São Paulo: DIFEL, 1983.

TWMW - Those Who Make Waves. Animas River Sound Sculpture. [Brian House, 2017]. Disponível em: http://www.thosewhomakewaves.com/home/2017/5/4/animas-river-sound-sculpture. Acesso em: 31 maio 2018.

VIDLER, Anthony. O campo ampliado da arquitetura. In: SYKES, A. Krista. O campo ampliado da arquitetura: Antologia teórica 1993-2009. Tradução de Denise Bottman. São Paulo: Cosac Naify, 2013. p.242-251.

ZEVI, Bruno. Saber ver a arquitetura. Tradução de Maria Isabel Gaspar, Gaëtan Martins de Oliveira. 6a ed. São Paulo: Editora WMF Martins Fontes, 2009 [1948]. 